$\begin{array}{cc}\text { ACADEMIA ROMÂNĂ } & \begin{array}{c}\text { Rev. Roum. Chim., } \\ \mathbf{2 0 2 0}, \text { 65(7-8), 693-698 }\end{array} \\ \text { Revue Roumaine de Chimie } & \text { DOI: 10.33224/rrch.2020.65.7-8.06 } \\ \text { http://web.icf.ro/rrch/ } & \end{array}$

\title{
KINETICS OF ISOTHERMAL IGNITION AND COMBUSTION OF SOME OXYGENATED VOCS ON PLATINUM WIRE
}

\author{
Valentin MUNTEANU, ${ }^{\mathrm{a}}$ Maria MITU, ${ }^{\mathrm{a}, \mathrm{b},{ }^{*}}$ Domnina RAZUS ${ }^{\mathrm{b}}$ and Dumitru OANCEA ${ }^{\mathrm{a}}$

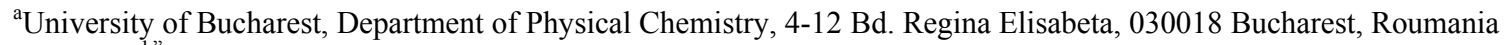 \\ b"Ilie Murgulescu" Institute of Physical Chemistry, Roumanian Academy, 202 Spl. Independentei, \\ 060021 Bucharest, Roumania
}

Received August 2, 2019

Three oxygenated Volatile Organic Compounds (VOCs): acetone, ethanol, and methyl tert-butyl ether (MTBE), frequently used in both industrial and domestic activities, were subjected to a kinetic study of catalytic oxidation with air on a platinum wire heated in isothermal regime. An isothermal technique previously described for volatile hydrocarbons was extended to the oxygenated volatile compounds obtaining valuable information on the ignition and subsequent combustion on and around the platinum surface. From the measurements of the electrical characteristics of the heating circuit, several properties like the critical ignition temperature, thermal flux emitted by the chemical reaction and induction time were measured. Their dependence on the gaseous mixture pressure, fuel concentration and platinum catalyst temperature resulted in the overall activation parameters of the combustion process.

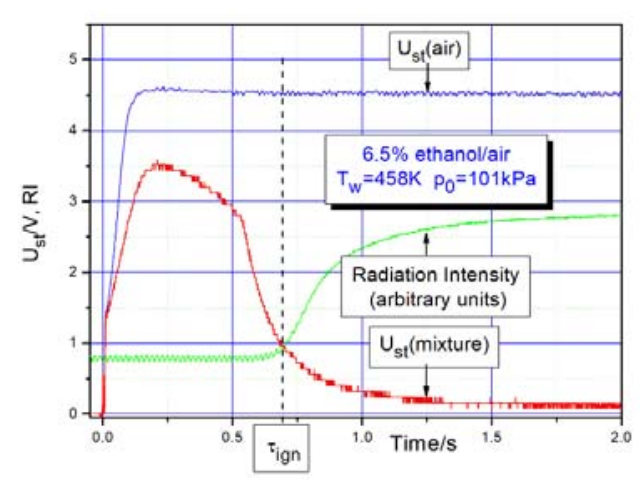

\section{INTRODUCTION}

The abatement or removal of Volatile Organic Compounds (VOCs), which resulted from either natural or anthropogenic sources, represent in our industrial era a subject of permanent concern. They constitute harmful pollutants and represent a threat for human health as well as an explosion risk. There are now many established procedures dedicated to the depollution process. The most effective one proved to be the catalytic removal, using noble or nonnoble metals as such or deposited on different supports like porous metal oxides $^{1-4}$ or structures of perovskite or spinel type.
The catalytic combustion is primarily of interest from practical viewpoint, to ensure clean air, without taking into account the mechanistic details. However, to improve the technique, the mechanistic research requires the knowledge of all local conditions like the existence of temperature and concentration gradients. Due to the exothermicity of the combustion reactions, important temperature gradients are established in the neighborhood of the metallic catalyst particles deposited on the porous support. A possible way to minimize these gradients was to work in quasiisothermal regime on a thin platinum wire. This was achieved using a quasi-rectangular

\footnotetext{
${ }^{*}$ Corresponding author: maria_mitu@icf.ro
} 
temperature profile applied on the wire, obtained by discharging a condenser and heating it subsequently by using a specially designed feeding circuit and measuring its characteristic properties. This technique has been subsequently applied to different hydrocarbon-air mixtures, obtaining valuable kinetic and mechanistic information ${ }^{6-14}$ and is supplemented here with oxygenated VOCsair mixtures. From the measured characteristic of the heating circuit and using calibration diagrams, a number of properties of the system like the critical ignition temperature, critical ignition energy, thermal flux emitted by the combustion reactions and the induction period as functions of the gaseous mixture pressure, fuel concentration or platinum catalyst temperature could be measured. ${ }^{15-18}$ The available models from literature allowed the evaluation of the overall activation parameters of the combustion reaction. ${ }^{18}$

Owing to the presence of both intrinsic and extrinsic oxygen in oxygenate VOCs-air mixtures, significant changes are expected to occur in their kinetics and mechanism. Among the numberless such systems, the mixtures acetone-air, ethanol-air, and MTBE-air were considered the most illustrative.

\section{RESULTS AND DISCUSSION}

Acetone-air mixtures. Acetone, $\left(\mathrm{CH}_{3}\right)_{2} \mathrm{CO}$, is a volatile, flammable liquid frequently used as solvent and for production of other valuable chemicals. Its mixtures with air are harmful for human health and present also explosion risks.

The measurements of the different characteristic properties for mixtures acetone-air allowed the determination of kinetics and mechanism of the combustion reaction on and around catalytic platinum wire. The critical ignition temperature, $T_{w}^{c r}$, is correlated with the total gaseous pressure, $p_{0}$, by Equation 1:

$$
p_{0}^{n} \cdot \exp \left(-E_{a} / R T_{w}^{c r}\right)=\text { const }
$$

where $n$ is the overall reaction order. ${ }^{5,713}$ The obtained data are illustrated in Fig. 1.

The activation parameters can be evaluated through a nonlinear regression from Equation 1.

On the other hand, the ignition delay, $\tau_{i}$, is correlated with the total gas pressure, $p_{0}$, and with the platinum catalyst temperature, $T_{w}^{c r}$, by an Equation of the form: ${ }^{8,10,11}$

$$
\tau_{i}=C t_{1} \cdot p_{0}^{-n} \cdot \exp \left(E_{a} / R T_{w}^{c r}\right)
$$

The activation energy can be also evaluated through linear regression at constant pressure as illustrated in Fig. 2, or from Equation 3 which gives the thermal flux emitted by the combustion reactions, ${ }^{5}\left(d Q_{R} / d t\right)_{\max }$ :

$$
d Q_{R} / d t=C t_{2} \cdot p_{0}^{n} \cdot \exp \left(-E_{a} / R T_{w}^{c r}\right)
$$

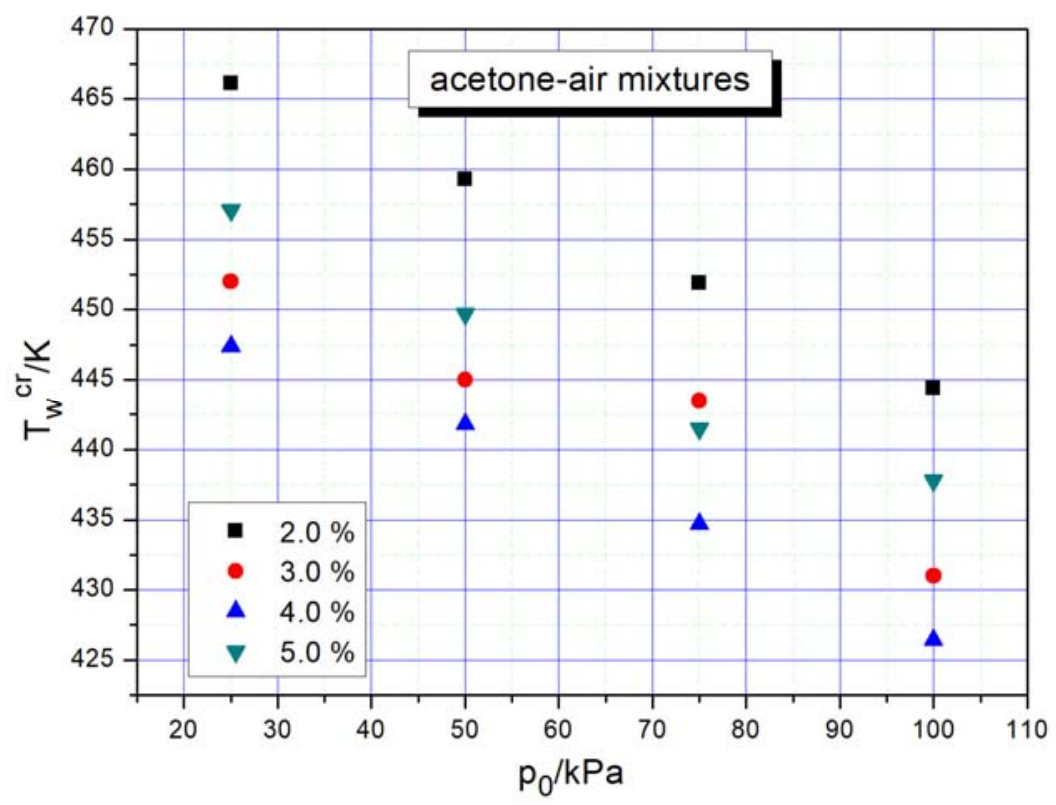

Fig. 1 - The dependence of the critical platinum wire temperature on the total gaseous pressure. 


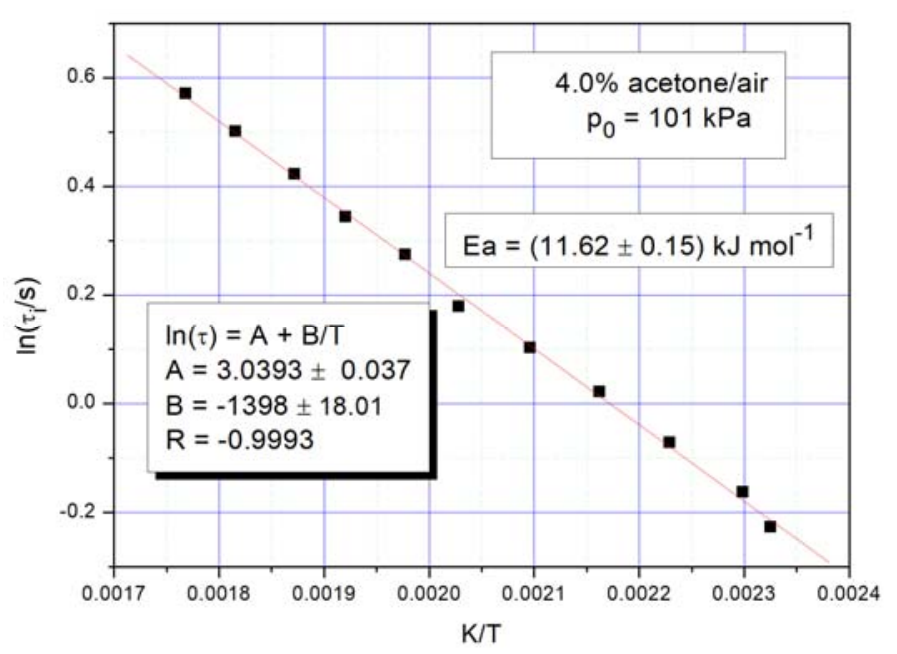

Fig. 2 - Linear regression of induction delay versus reciprocal temperature.

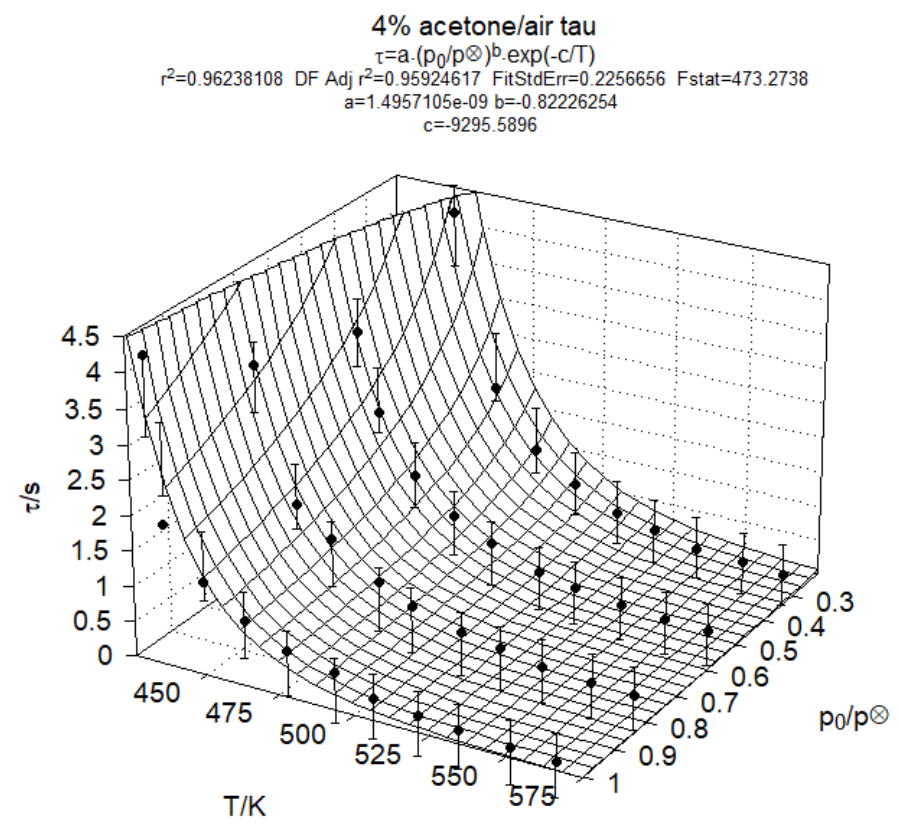

Fig. 3 - A 3D plot and the resulted averaged kinetic parameters, where $p^{\otimes}$ is the reference pressure taken as $101 \mathrm{kPa}$. The resulted overall reaction order is $n=0.82$, and overall activation energy is $E a=77 \mathrm{~kJ} \mathrm{~mol}^{-1}$.

The linear regression (3) at constant pressure for a $4 \%$ acetone-air mixture at $101 \mathrm{kPa}$ gave $\ln \left(d Q_{R} / d t\right)_{\max }=(3.0357 \pm 0.0370)-(1398 \pm$ 18) $/ T_{w}^{c r}$ with a correlation coefficient $\mathrm{R}=-0.993$ and an activation energy $E a=(11.62 \pm 0.15) \mathrm{kJ} \mathrm{mol}^{-1}$.

The calculated activation energies differ significantly from each other, as well as from that resulted using the nonlinear $3 \mathrm{D}$ regression for the same mixture, given in Fig. 3.

Such differences come from the specific hypotheses used in each model. The values obtained from $\tau_{i}$ and from $\left(d Q_{R} / d t\right)_{\max }$ refer to different instants of the combustion process, while that resulted from the $3 \mathrm{D}$ regression is an average value.

Ethanol-air mixtures. The ethanol $\left(\mathrm{CH}_{3} \mathrm{CH}_{2} \mathrm{OH}\right)$ is also a volatile, flammable liquid produced naturally by the fermentation of sugars or petrochemically and used in beverages, in synthesis of other compounds, as solvent, as fuel, or as fuel additive.

The analysis of the ethanol-air mixtures properties confirms their explosion risks giving also several specific characteristics for oxygenated VOCs. Our measurements of combustion on the platinum wire showed important differences between radiation emission (mainly in VIS and IR) in air and in fuel-air 
mixtures. The time evolution of this radiation emission supplements our knowledge on the ignition period, as illustrated in Fig. 4.

It can be seen that the localization of the ignition delay using the response of the feeding circuit (the curve $U_{\text {st }}$ versus time) is virtually the same with that indicated by the curve giving the variation of radiation intensity in time, suggesting another possibility to evaluate the ignition delay.

The activation energy can also be evaluated from linear regressions on Equations 2 or 3 at constant pressure as illustrated in Figs. 5 and 6.

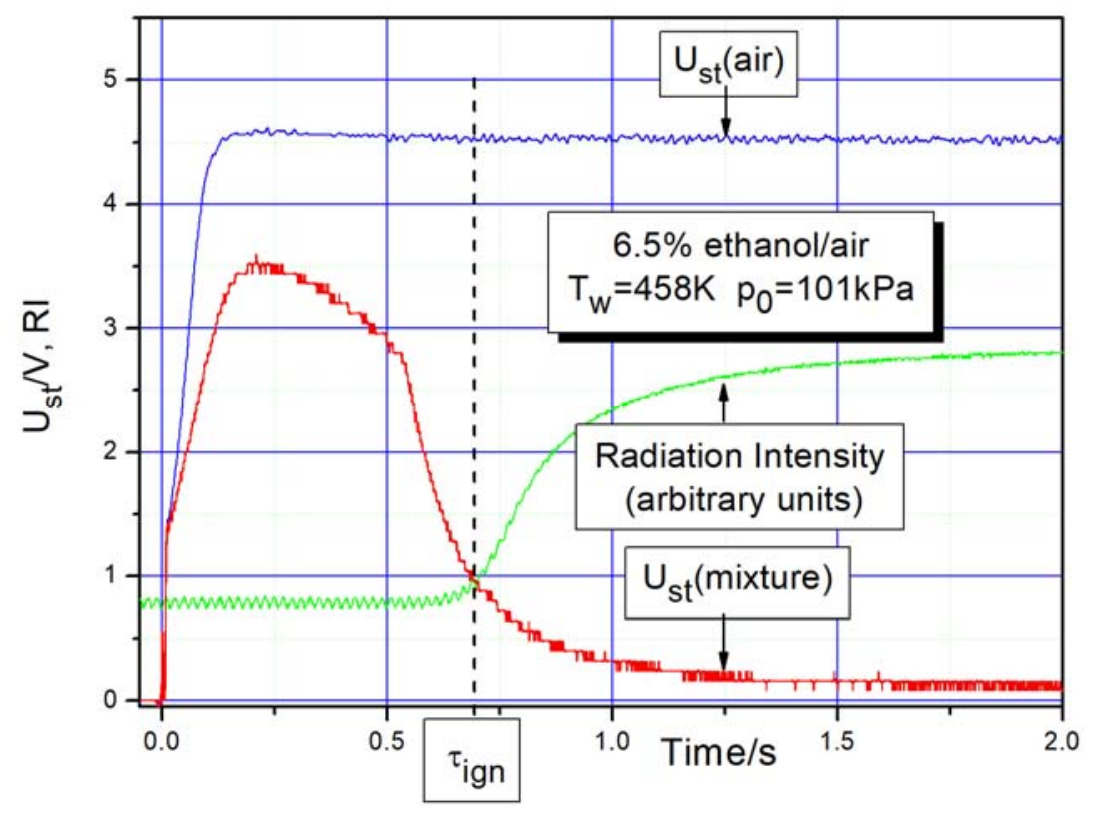

Fig. 4 - Variation of voltage on the standard resistor, $U_{\text {st }}$, showing the ignition delay $\tau_{i g n}$ indicated on both electrical and optical curves.

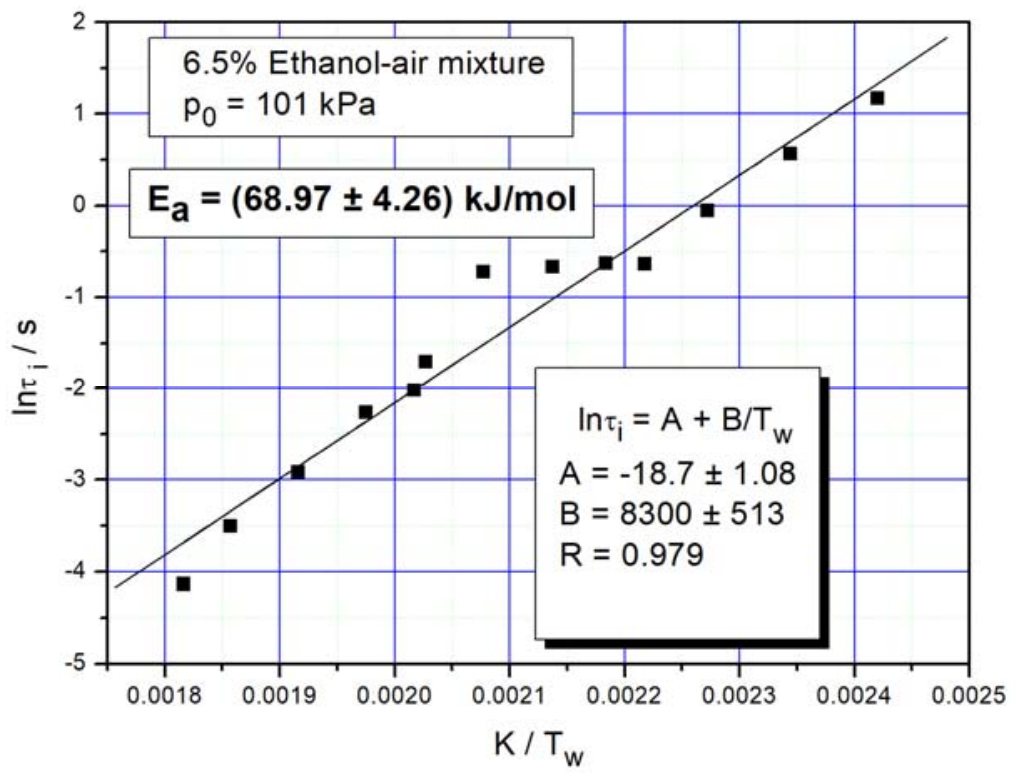

Fig. 5 - Variation of ignition delay versus reciprocal temperature for $6.5 \%$ ethanol-air.

The ignition delay for this system varies within the same range with acetone-air mixtures and the activation energies are not very different from each other $\left(54\right.$ and $\left.69 \mathrm{~kJ} \mathrm{~mol}^{-1}\right)$.
On the other hand, the linear regression on Equation 3 gives: 


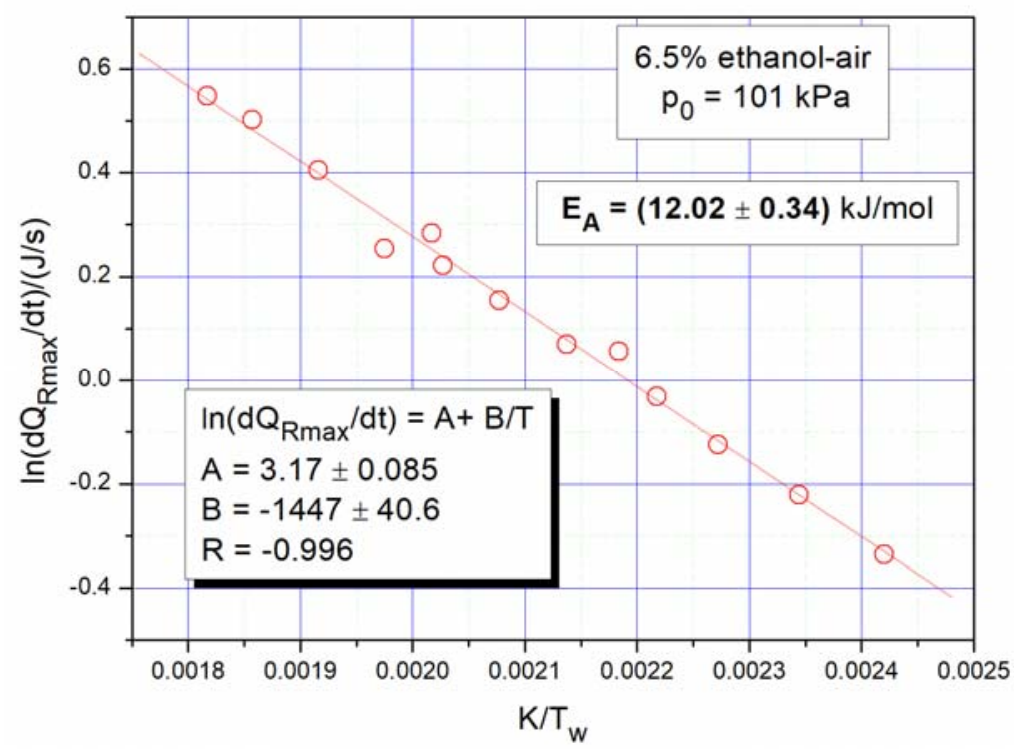

Fig. 6 - Variation of the thermal flux emitted by the combustion reactions, $\left(d Q_{R} / d t\right)_{\max }$ versus reciprocal temperature for $6.5 \%$ ethanol-air.

The activation energy evaluated for both acetone-air and ethanol-air systems using this procedure gave $E a \approx 12 \mathrm{~kJ} \mathrm{~mol}^{-1}$, significantly lower than the previous ones.

MTBE-air mixtures. The tert-butyl methyl ether (MTBE), $\left(\mathrm{CH}_{3}\right)_{3} \mathrm{COCH}_{3}$, is also a volatile, flammable compound used primarily as a blending component of gasoline, to raise its octane number in order to replace tetraethyl lead.

The experimental measurements for MTBE-air mixtures show, as for the systems discussed above, ignition on platinum wire occurs after different delays, as illustrated in Fig. 7.
From the variation of the thermal flux emitted by the combustion reactions, $\left(d Q_{R} / d t\right)_{\max }$, resulted $n=0.21$ and $E a=13 \mathrm{k} \mathrm{J} \mathrm{mol}{ }^{-1}$ showing again significant differences between the two procedures.

From the regressions (2) and (3) at $p_{0}=101 \mathrm{kPa}$ resulted: $\ln \left(\tau_{i} / \mathrm{s}\right)=(-19.01 \pm 1.15)+(72.5 \pm$ $6.0) / T_{w}^{c r}$ and $\ln \left(d Q_{R} / d t\right)_{\max }=(3.159 \pm 0.034)$ - $(12.20 \pm 0.14) / T_{w}^{c r}$ with the same significant differences between the two models.

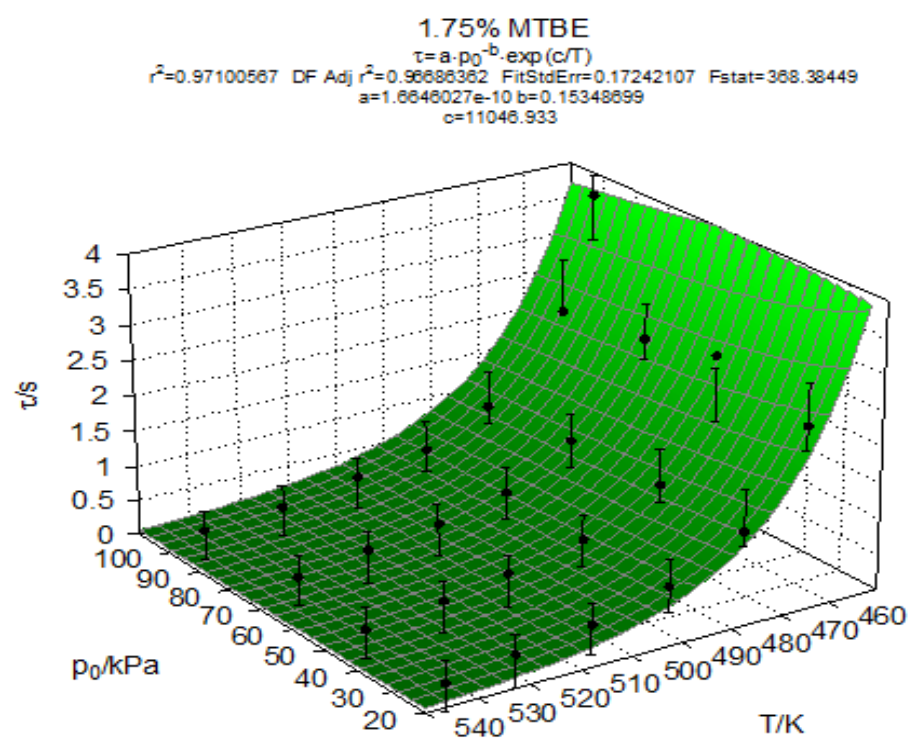

Fig. 7 - Variation of ignition delay with mixture pressure and catalyst temperature with $n=0.15$ and $E a=92 \mathrm{~kJ} \mathrm{~mol}^{-1}$. 


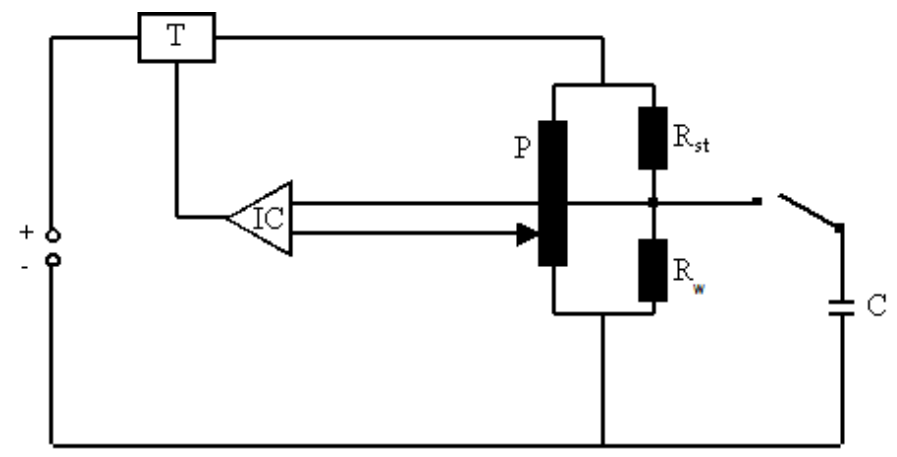

Fig. 8 - Schematic diagram of the specially designed feeding circuit of the catalytic platinum wire.

\section{EXPERIMENTAL}

The experimental measurements were carried out using the equipment and procedure described in details previously, ${ }_{5}$ and given schematically in Fig. 8, where the platinum wire (99.99\% from Aldrich) with resistance $R w$, the standard resistor with resistance $R s t$ and potentiometer $P$ form a Wheatstone bridge.

The discharge of the condenser $C$, previously charged to a suitable voltage (established by trial and error) across the wire in less than $1 \mathrm{~ms}$ ensures the temperature jump, while the integrated circuit $I C$ senses the bridge and adjust the feed voltage through the power transistor $T$. The voltage Ust across the standard resistor is monitored with a Tektronix TDS 210 oscilloscope. All experiments were carried out in an explosion cell previously ${ }^{8,10,11}$ described, supplemented with a Si PIN S 123 photodiode (from Hamamatsu) connected to the second channel of oscilloscope.

\section{CONCLUSIONS}

The present paper deals with the measurements and discussion of isothermal ignition and subsequent combustion of three oxygenated VOCs using a procedure described in several previous papers concerned with the explosivity of hydrocarbon-air mixtures.

The study was initiated to detect possible differences induced by the presence of both intrinsic and extrinsic oxygen in oxygenate VOCsair mixtures.

The general trend was similar with that found for hydrocarbon-air mixtures ${ }^{5-17}$, with some characteristics induced by the specificity of system.

The overall activation parameters $(n \approx 0.21$ 0.82 and $E a \approx(12-92) \mathrm{kJ} \mathrm{mol}^{-1}$ are approximately within the same range with those for hydrocarbon-air mixtures ${ }^{5-17}(n \approx 0.16-0.82$ and $E a \approx(5-100) \mathrm{kJ} \mathrm{mol}^{-1}$, dependent on the adopted model.
The methodology developed for study of the isothermal ignition and subsequent combustion on platinum wire for hydrocarbon-air mixtures can be equally applied for similar studies for oxygenated VOCs-air mixtures.

\section{REFERENCES}

1. J. F. Lamonier, Catalysts, 2016, 6, 7, 1-3.

2. S. Ojala, N. Koivikko, T. Laitinen, A. Mouammine, P. K. Seelam, S. Laassiri, K. Ainassaari, R. Brahmi and R. L. Keiski, Catalysts, 2015, 5, 1092-1151.

3. S. Sultana, A. M. Vandenbroucke, C. Leys, N. de Geyter and R. Morent, Catalysts, 2015, 5, 718-746.

4. M. S. Kamal, S. A. Razzak and M. M. Hossain, Atmospheric Environment, 2016, 140, 117-134.

5. D. Oancea, D. Razus, M. Mitu and S. Constantinescu, Rev. Roum. Chim., 2002, 47, 91-97.

6. D. Oancea, M. Mitu, E. Pincu and D. Razus, Rev. Roum. Chim., 2004, 49, 391-397.

7. D. Oancea, D. Razus and M. Mitu, Rev. Roum. Chim., 2005, 50, 991-997.

8. D. Oancea, O. Staicu, V. Munteanu and D. Razus, Catal. Lett., 2008, 121, 247-254.

9. O. Staicu, V. Munteanu, D. Razus and D. Oancea, Rev. Roum. Chim., 2008, 53, 277-282.

10. O. Staicu, V. Munteanu and D. Oancea, Catal. Lett., 2009, 129, 124-129.

11. O. Staicu, D. Razus, V. Munteanu and D. Oancea, Centr. Eur. J. Chem., 2009, 7, 478-485.

12. O. Staicu, V. Munteanu and D. Oancea, Rev. Roum. Chim., 2009, 54, 287-292.

13. O. Staicu, V. Munteanu and D. Oancea, Studia Univ. Babes-Bolyai Chem., 2009, 54, 193-202.

14. D. Oancea, V. Munteanu and D. Razus, J. Therm. Anal. Calorim., 2010, 102, 993-1000.

15. D. Oancea, O. Staicu and V. Munteanu, Rev. Roum. Chim., 2010, 55, 211-216.

16. D. Oancea, V. Munteanu, D. Razus and M. Mitu, Rev. Roum. Chim., 2011, 56, 211-216.

17. M. Mitu, V. Munteanu, D. Razus and D. Oancea, Rev. Roum. Chim., 2014, 59, 727-732.

18. L. E. Ashman and A. Büchler, Comb. Flame, 1961, 5, 113-21. 